\title{
¿VISIBILIZACIÓN O INVISIBILIZACIÓN DE LA MUJER EN EL DEPORTE COSTARRICENSE?
}

WOMEN'S VISIBILIZATION, OR INVISIBILIZATION IN COSTA RICAN SPORTS?

Blanca Luz Sojo Mora ${ }^{1}$

Edwin Coto Vega ${ }^{2}$

\section{Resumen}

El cambio de los roles femeninos, de la mujer ama de casa y de la mujer de familia a mujer deportista, ha venido presentándose desde hace algunos años, con el inicio de la participación a nivel nacional e internacional de los movimientos feministas. Por siglos, el deporte fue vedado a la mujer, por lo que se acepta que su incorporación fue tardía. Lo importante es que logró ingresar en un espacio que por mucho tiempo fue exclusivo para los hombres, y que poco a poco su participación debe mostrarse más, con ayuda de las instituciones educativas, la familia y, sobre todo, los medios de comunicación.

A pesar de que la participación de la mujer en el deporte es un hecho, los resultados muestran una invisibilización en el escenario público. Son muy pocas las noticias e imágenes de mujeres deportistas, directivas y entrenadoras; la mayor parte del espacio en las secciones deportivas estudiadas se dedica a los hombres, lo que refleja no solo invisibilización, sino opresión, exclusión y discriminación, como resultado de un sistema patriarcal.

Palabras clave: mujer, deporte, estereotipos, sistema patriarcal, opresión.

\section{Abstract}

The change of female roles, from housekeeper and mother to sportswoman, started a few years ago when feminist movements began to participate nationally and internationally. For ages, sports were forbidden for women, which resulted in a belated inclusion. What matters is that women managed to make it into a world traditionally reserved for men, and that such an involvement must be increasingly shown, with the help of educational institutions, families and, particularly, printed media.

Even though women's participation in sports is a fact, the results reveal invisibilization in the public scene. News and pictures of sportswomen, female managers and coaches are very scarce. Most of the space in sport pages is devoted to men, which reflects not only invisibilization, but also oppression, social exclusion and discrimination as a result of a patriarchal system.

Keywords: women, sport, stereotypes, patriarchal system, oppression.

Fecha de recepción: 15 de julio de 2014

Fecha de aprobación: 6 de noviembre de 2014

1 Docente e investigadora de la Universidad de Costa Rica, sede del Atlántico. Correo electrónico: blancaluzsojo@gmail.com

2 Docente e investigador de la Universidad de Costa Rica, sede del Atlántico. Correo electrónico: cotoedwin@gmail.com 
Para citar este artículo:

Sojo, B., Coto, E. (2014). ¿Visibilización o invisibilización de la mujer en el deporte costarricense?. Revista Lúdica Pedagógica, (20), 47-58.

\section{INTRODUCCIÓN}

Nada es estático, pues todo cambia. La sociedad ha venido cambiando, desde una sociedad capitalista marcada por el surgimiento de la tecnificación, el desarrollo de las fábricas y sus implicaciones (la modernidad, el énfasis en la razón y la ciencia, la aparición del consumismo) hasta una posible sociedad donde se cuestiona la verdad y la representación de la realidad. La sociedad cambia al mismo tiempo que los sujetos, y con ellos cambian sus acciones, comportamientos y pensamientos. Sin embargo, en el caso de la mujer esas modificaciones han estado reguladas por la estructura patriarcal.

Varios son los ámbitos que han cambiado a raíz de las transformaciones sociales: el político, el económico, el laboral, el familiar, incluso el tiempo para el ocio, la recreación o la práctica deportiva. El deporte es un área donde se pueden observar claramente las limitaciones de la población femenina en cuanto a participación, así como en la promoción y divulgación por parte de los medios de comunicación escrita.

En este artículo se investiga la participación de la mujer en el deporte a nivel nacional, se parte de la historia para identificar el protagonismo masculino en la práctica deportiva y su evolución, en relación con la incursión de la mujer en ella. El trabajo se basa en el análisis cuantitativo de dos medios de comunicación escrita: se comparan cantidades de texto, imágenes y periodistas, en relación con los hombres y las mujeres.

Además, se estudian estereotipos relacionados con el deporte femenino y el papel que cumplen los medios de comunicación en su validación. Lo anterior permitirá analizar si se requiere el cambio del constructo "femenino" en el deporte costarricense. Para ello, se propondrán ideas sobre la posibilidad de lograr la construcción de nuevos sujetos femeninos en el deporte, a partir de una perspectiva de género. Todo lo anterior es fundamental para responder al cuestionamiento de la visibilización o invisibilización de la mujer en el deporte y, de esta manera, dilucidar su participación, no solo como atleta sino como protagonista en el ámbito deportivo.

\section{HISTORIA}

La Comisión Nacional de Cultura Física y Deporte en colaboración con el Instituto Nacional de las Mujeres de
Ciudad de México (s. f.) hace una referencia histórica de la evolución del deporte y la participación de la mujer, con énfasis en la influencia de la cultura griega en esta actividad. A continuación, una brevísima referencia a la historia del deporte:

Para el 766 antes de Cristo se realizaron en Olimpia los primeros Juegos Olímpicos en honor a Zeus, los cuales desaparecieron por mandato de Teodosio I en 392 después de Cristo. Esos primeros juegos enfocaron la habilidad guerrera y atlética del hombre, mientras la mujer no participó de las justas, con excepción de los de Esparta. Posteriormente, en 1888, Pierre de Fredy, barón de Coubertain, creó el Comité para la Propagación de los Ejercicios Físicos en la Educación, y más tarde, en 1894, realizó un "Congreso Internacional" para la instauración de los Juegos Olímpicos de la era moderna. El barón de Coubertin dejó claro que la mujer no participaría en ellos, pues se creía que las mujeres podrían adquirir terribles enfermedades, incluida la esterilidad. (Comisión Nacional de Cultura Física y Deporte e Instituto Nacional de las mujeres, pp. 15-16)

Lo anterior muestra que en los orígenes del deporte hubo una posición excluyente, reducida a los hombres. Como señala Barbero (1993), la hombría era definida como un "ideal moral", como una auténtica forma de ser y, desde esa perspectiva, "ser deportista" equivalía a ser caballeroso, viril y también poco dado a complicaciones de orden intelectual.

Sin embargo, según la Comisión Nacional de Cultura Física y Deporte y el Instituto Nacional de las Mujeres (s. f.), estas se negaron a aceptar la determinación de Pierre de Coubertin, y la francesa Alice Millat fundó, en 1922, los Juegos Olímpicos Femeninos, realizados en París y basados en el atletismo, con subsecuentes ediciones en Gotemburgo (1926) y en Praga (1930), luego de lo cual su organismo se integró a la Federación Internacional de Atletismo para dar cabida a las mujeres de manera oficial.

Igualmente, la Comisión Nacional de Cultura Física y Deporte en colaboración con el Instituto Nacional de las Mujeres de Ciudad de México (s. f.) expresan que Estados Unidos fue uno de los primeros países en impulsar la participación de las mujeres en el deporte, cuando en la década de 1970 el entonces presidente, Richard Nixon, firmó el Título IX, que garantizó iguales derechos a niñas y mujeres en todos los aspectos de la educación, incluido el atletismo. Lo anterior permitió abrir las puertas a las mujeres en la práctica de este deporte. Este manifiesto generó patrocinio y becas en universidades para las mujeres deportistas, lo cual tuvo un gran impacto en América Latina 
Rodríguez, Martínez y Mateos (2004) mencionan que, a partir de 1980, el Comité Olímpico Internacional estableció que, de manera obligatoria, todos aquellos deportes del programa olímpico deberían contar con la participación femenina. La siguiente tabla, tomada de Deporte y discriminación por sexo: fútbol, remo y salto de esquí (Tusell, 2009) refleja la evolución de la mujer desde los Juegos Olímpicos de Atenas, en 1896, hasta los de Pekín, en 2008.

Tabla 1. Historial sobre la participación de la mujer en los Juegos Olímpicos

\begin{tabular}{|c|c|c|c|c|c|}
\hline Sede & Total atletas & Total mujeres & Sede & Total atletas & Total mujeres \\
\hline Atenas 1896 & 241 & 0 & Roma 1960 & 5.338 & $611(11,45 \%)$ \\
\hline París 1900 & 997 & $22(2,21 \%)$ & Tokio 1964 & 5.151 & $678(13,16 \%)$ \\
\hline San Luis 1904 & 651 & $6(0,92 \%)$ & México 1968 & 5.516 & $781(14,16 \%)$ \\
\hline Londres 1908 & 2.008 & $37(1,84 \%)$ & Munich 1972 & 7.134 & $1.059(14,84 \%)$ \\
\hline Estocolmo 1912 & 2.407 & $48(1,99 \%)$ & Montreal 1976 & 6.084 & $1.260(20,71 \%)$ \\
\hline Amberes 1920 & 2.626 & $65(2,48 \%)$ & Moscú 1980 & 5.179 & $1.115(21,53 \%)$ \\
\hline París 1924 & 3.089 & $135(4,37 \%)$ & Los Ángeles 1984 & 6.289 & $1.566(22,93 \%)$ \\
\hline Ámsterdam 1928 & 2.883 & $277(9,61 \%)$ & Seúl 1988 & 8.391 & $2.194(26,15 \%)$ \\
\hline Los Ángeles 1932 & 1.332 & $126(9,46 \%)$ & Barcelona 1992 & 9.356 & $2.704(28,9 \%)$ \\
\hline Berlín 1936 & 3.963 & $331(8,35 \%)$ & Atlanta 1996 & 10.318 & $3.512(34,04 \%)$ \\
\hline Londres 1948 & 4.104 & $390(9,50 \%)$ & Sydney 2000 & 10.651 & $4.069(38,20 \%)$ \\
\hline Helsinki 1952 & 4.955 & $519(10,47 \%)$ & Atenas 2004 & 10.568 & $4.306(40,75 \%)$ \\
\hline Melbourne 1956 & 3.314 & $376(11,35 \%)$ & Pekín 2008 & 11.196 & $4.746(42,39 \%)$ \\
\hline
\end{tabular}

Fuente: Comisión Mujer y Deporte (Comité Olímpico Español, citado por Tusell [2009]).

La información anterior refleja un aumento en la participación de atletas femeninas desde los Juegos Olímpicos de 1900 hasta los de Pekín 2008, pero no establece equidad con la participación masculina. Los datos demuestran un acceso tardío de la mujer al ámbito deportivo.

\section{LA PRÁCTICA DEPORTIVA COMO FENÓMENO SOCIAL}

El deporte tiene impacto en cada sociedad en ámbitos políticos, económicos y culturales. Existe un mercado cultural que mueve grandes cantidades de dinero, que logra impactar a las personas a través de los medios de comunicación, que han convertido al deporte en un espectáculo mediático.

En la medida en que un grupo social es apartado de la práctica deportiva por razones de sexo, clase social, raza u otra condición social o biológica, se ve privado de ventajas que le proporcionaría el deporte. En muchas ocasiones, el deporte es clasista, se perfila solo para un grupo de personas que tienen cierto poder adquisitivo y que tienen acceso a los lugares de práctica, implemen- tos e indumentaria. Asimismo, existen deportes más populares que pueden ser practicados por la mayoría de las personas.

Igualmente, la sociedad ha determinado deportes que son practicados por hombres y otros exclusivamente por las mujeres. Lo anterior no responde solo a diferencias biológicas, sino también a la identidad, al rol de género y a los estereotipos. Esta concepción influye en la forma de pensar, sentir y actuar de un deportista o sujeto.

Macías (1999) destaca la influencia de los movimientos feministas en Estados Unidos sobre la mujer y el deporte, a partir de la década de 1980. Algunas de las ideas que predominaron fueron: el deporte como una institución patriarcal, ideología sexista en el deporte y el hecho de que las mujeres no son hombres. De esta manera el deporte empezó a estudiarse como un fenómeno social relevante, gracias a las investigaciones de los movimientos feministas.

Vargas (2002) aclara que el feminismo latinoamericano inicia con un movimiento popular de mujeres de clase media, provenientes de la izquierda, que expresaron 
diferentes formas de entender y actuar la subordinación y la exclusión de las mujeres. Estas ideas generaron nuevos saberes y visibilizaron la realidad. Asimismo, Vargas (2002) indica que el movimiento feminista produjo "un conjunto de rupturas epistemológicas y la construcción de nuevos paradigmas y nuevas pautas interpretativas alrededor de la realidad; su resultado fue el desarrollo de nuevas cosmovisiones" (p. 308).

Esos nuevos saberes y conocimientos tocaron el ámbito deportivo, produciendo ideas revolucionarias y emancipadoras. En la actualidad la práctica deportiva tiene un significado basado en la sexualización de la actividad física de las mujeres, enfocado en la imagen corporal, donde es prioridad el control del peso, la apariencia y el atractivo físico (Macías, 1999). Así surge una nueva concepción del deporte femenino moderno, centralizado en la imagen corporal, bajo la medida de la belleza, la delgadez y la juventud, en busca del cuerpo perfecto y el deporte como medio para ese fin. Cuevas (2009) en su estudio Cuerpo, feminidad y consumo llega a la conclusión de que "existe una exaltación del cuerpo que se caracteriza por culto a la imagen estética" (p. 90).

\section{ESTEREOTIPOS DE LA MUJER EN EL DEPORTE}

Los estereotipos marcan el comportamiento al determinar una serie de rasgos que identifican tanto al hombre como a la mujer. Rodríguez et al. (2004) mencionan que uno de los estereotipos presentes a lo largo de la historia es el de considerar que algunos deportes son más apropiados para las mujeres y otros para los hombres. Lo anterior asigna características a la mujer como el ser delicada, frágil y sumisa, mientras que los hombres deben reflejar potencia, fuerza, velocidad y resistencia.

La mujer en el deporte es vista desde su aspecto biológico, básicamente por su capacidad para la maternidad, como lo anotan Rodríguez, Martínez y Mateos (2004). Por ello a la mujer no le ha sido fácil asumir su corporeidad desde la libertad personal. En cambio, se ha propiciado la consideración implícita de que el cuerpo de la mujer no es un cuerpo para ella sino para los demás: en primer lugar, como madre y receptora de los hijos; en segundo lugar, como conquista y posesión del varón para el que debe estar bella y se debe resguardar; finalmente, desde un punto de vista social, como reproductora de la propia sociedad.

Los anteriores factores han impedido secularmente que la mujer pueda vivir su cuerpo en función de ella misma y tenga una experiencia corporal propia y gratuita que le permita las satisfacciones que el individuo obtiene con las actividades que realiza (p. 2004).

A causa de la influencia androcéntrica en la sociedad, se ha generado una serie de estereotipos en torno a la concepción del cuerpo de la mujer, sus posibilidades y funciones, que refuerzan estereotipos sobre la utilización de los espacios públicos para el juego. Villanova y Soler (2008) explican cómo las niñas juegan dentro de la casa, usan espacios pequeños y rincones marginados, mientras que los niños juegan en los espacios amplios fuera de la casa, con mayores posibilidades de movimiento. Estas mismas autoras aseveran que ocurre lo mismo en la edad adulta. Las mujeres prefieren espacios internos, poco visibles, como gimnasios, mientras los hombres espacios externos y abiertos. Esto muestra una invisibilización de la mujer en los espacios públicos, desde la infancia, que acarrea consecuencias en años posteriores. Lo anterior parece ser un reflejo del lugar que ocupan las mujeres en la sociedad, destinada a espacios privados.

Otros estereotipos son que las mujeres no están interesadas en el deporte y no son aptas para desarrollar este tipo de actividades por sus características biológicas, la afirmación de que a las mujeres que practican deporte se les cataloga como masculinas o marimachos, quizá por su desarrollo muscular. Otro estereotipo, aún más degradante y descalificador, es que el espacio deportivo propicia la homosexualidad femenina.

\section{POSICIÓN DE LOS MEDIOS DE COMUNICACIÓN}

Los medios de comunicación fomentan el estereotipo del deporte como una práctica exclusiva para el hombre. Alexander (1994, citado por Macías 1999) realizó un estudio en Inglaterra sobre la influencia de los medios de comunicación en el deporte femenino. Este autor analizó siete periódicos durante el Campeonato del Mundo de Atletismo de 1991, y las Olimpiadas de 1992; estudió detalladamente las líneas escritas, los titulares y las fotografías, con lo que demostró una desproporción en cuanto a la cobertura de la prensa en el deporte femenino y masculino.

Birrell y Theberge (1994, citados por Macías 1999) establecen una serie de constantes que prevalecen en los medios de comunicación, sin distinción de tipos ni nacionalidad:

- Baja representación de las mujeres atletas en los medios. 
- Marginalización de las mujeres atletas; las noticias deportivas femeninas son aisladas y sin importancia, en comparación con los logros masculinos.

- Sexualización de las mujeres atletas: las fotografías enfocan posturas e indumentaria desde una perspectiva más erótica que deportiva.

- Descripción de la implicación de la mujer en el deporte como algo trágico.

- La construcción de atletas como innaturales.

Los medios de comunicación han hecho todo un espectáculo de la práctica deportiva. Tal como lo menciona Kellner (s. f.), desde la aparición de la televisión en 1940, el deporte se convirtió en un campo fértil para la propaganda, marcando una sociedad de consumo: por medio del deporte promocionan sus productos. El deporte pasó a ser todo un espectáculo, los eventos deportivos deben causar sensaciones atractivas y emocionantes en los televidentes y observadores. Kellner (s. f.) reitera lo anterior, al describir estos eventos acompañados con música, animadoras, mascotas gigantes, luces, lo que permite crear todo un ambiente propio de un "espectáculo mediático".

\section{NUEVO CONSTRUCTO DE MUJER}

La mujer corresponde a un constructo y a una episteme occidental y moderna, a un saber ya construido por un colectivo, en oposición a la individualidad. Según una de las acepciones del Diccionario de la lengua española (Real Academia Española, 2001), episteme es un conjunto de conocimientos que condicionan la forma de entender e interpretar el mundo en una época específica.

A lo largo del tiempo, la mujer ha sido enmarcada en una posición disminuida en comparación con el hombre, bajo una sociedad patriarcal que consolida numerosos estereotipos de vieja data, que han sido afirmados por la sociedad con el aporte de los medios de comunicación.

Foucault (1968) indica que para construir una episteme es fundamental entender cómo se experimentan los signos y su lenguaje. En realidad, lo que la gente habla y escribe sobre la mujer está muy relacionado con el cuerpo, la belleza y la estética; el discurso de los otros sobre lo femenino está erotizado y estetizado.

Desde la teoría de la Différance de Derrida (1968) el discurso se puede deconstruir, llevando las estructuras al límite. De manera que cuando se hable, la persona sea consciente de lo que dice, alejándose de todo objeto significante, para que el lenguaje no marque las diferencias, las cuales son producidas. Esto se alcanza separando lo interior de lo exterior, visto el lenguaje como una exteriorización del significado interior; pensando desde la diferencia, situándose en el límite de la episteme, saliendo de los mismos planteamientos, desde una nueva racionalidad. En cuanto a la mujer, no hay una verdad y un significado únicos ya que ella no es estática ni ahistórica. Por tanto, los significados y las representaciones de la mujer pueden deconstruirse.

Las prácticas discursivas de la sociedad pueden marcar una división dicotómica entre hombre y mujer, que genera una cadena de pensamientos y conocimientos; pero a la vez, las prácticas discursivas pueden romper estereotipos. Si todo es cuestionable para Derrida (1968), se puede volver a construir nuevamente, viendo en lo visible lo invisible, mirando en la mujer lo que ha sido invisibilizado por muchos años, cuestionando lo naturalizado. Como afirma Foucault (1968) "La invisibilidad profunda de lo que se ve es solidaria de la invisibilidad de quien ve".

La realidad de la mujer en la sociedad es construida por "nosotros", pero esa realidad se puede modificar, dejando de ser pasivos y simples espectadores; colonizando la propia vida, que puede cambiar y redefinirse. Las mujeres deben tener claro lo que menciona Hall (s. f.): "las personas no están irrevocablemente e indeleblemente adscritas a las ideas que deben tener"; pueden tomar sus propias decisiones, pueden reorientar lo que es ser mujer, dejando de lado lo que es para los otros.

Este mismo autor brinda un excelente ejemplo en torno a cómo una palabra no tiene una connotación fija, de manera que los significados pueden cambiar de un concepto negativo a uno positivo. Hall (s. f.) explica cómo el concepto de negro experimentó un giro de 180 grados: de tener una connotación peyorativa (ignorante, incivilizado, incompetente), pasó a tener una connotación de herencia y origen de la población africana y representante de la esencia cultural, así se constituyó un nuevo sujeto colectivo. Si el concepto negro cambió de un significado negativo a uno positivo, eso quiere decir que el significado de mujer y de mujer deportista puede modificarse.

\section{CASO: DEPORTE FEMENINO EN COSTA RICA}

El Instituto Nacional de las Mujeres de Costa Rica (Inamu, 2011), en su página de internet, hace una mención sobre la Galería Costarricense del Deporte, que se creó en 1969 para honrar a los deportistas nacionales. Según el Inamu, en esta galería se brinda homenaje a 123 deportistas, de los cuales solamente 11 son mujeres. 
A continuación se hace una breve referencia de las 11 mujeres que se encuentran en la Galería del deporte:

Tabla 2. La mujer en la galería del deporte costarricense

\begin{tabular}{|c|c|c|c|}
\hline Deportista & Disciplina & Época & Logros \\
\hline $\begin{array}{l}\text { Cristina Lizano } \\
\text { Quirós }\end{array}$ & Baloncesto & 1917-1946 & $\begin{array}{l}\text { Promovió el baloncesto en secundaria, fundó varios } \\
\text { equipos. Antecesora de la Escuela de Educación Física, UCR. }\end{array}$ \\
\hline $\begin{array}{l}\text { Lidia Vargas } \\
\text { Campos }\end{array}$ & Baloncesto & 1932-1939 & $\begin{array}{l}\text { Fundó junto a otras amigas el equipo de baloncesto } \\
\text { Danubio Azul. Jugadora de primera division. }\end{array}$ \\
\hline $\begin{array}{l}\text { Margarita } \\
\text { Martínez } \\
\text { Hernández }\end{array}$ & Baloncesto & 1934-1939 & $\begin{array}{l}\text { Formó parte del equipo de baloncesto del } \\
\text { Club Sport La Libertad, Colegio Superior } \\
\text { de Señoritas y a nivel internacional. }\end{array}$ \\
\hline Avis Mc Lean Gray & Baloncesto & $1937-1940$ & $\begin{array}{l}\text { Una de las más brillantes jugadoras de baloncesto } \\
\text { de todos los tiempos en Costa Rica. Integró } \\
\text { el equipo del Colegio Superior de Señoritas; } \\
\text { con este equipo ganó en forma invicta. }\end{array}$ \\
\hline $\begin{array}{c}\text { Margarita } \\
\text { Segreda Víquez }\end{array}$ & Baloncesto & 1943 & $\begin{array}{l}\text { Titular del equipo del Colegio Superior de señoritas. } \\
\text { Seleccionada nacional. Jugó a nivel internacional. }\end{array}$ \\
\hline $\begin{array}{l}\text { Yolanda } \\
\text { Britton Riley }\end{array}$ & $\begin{array}{l}\text { Atletismo } \\
\text { Baloncesto }\end{array}$ & 1956-1962 & $\begin{array}{l}\text { Participó en olimpiadas intercolegiales: medalla de } \\
\text { oro } 50 \text { metros planos. Jugadora de baloncesto en } \\
\text { 1960, se declara mejor encestadora. Seleccionada } \\
\text { nacional. Participó a nivel internacional }\end{array}$ \\
\hline $\begin{array}{l}\text { Mayra Soto } \\
\text { Hernández }\end{array}$ & Atletismo & 1960-1968 & $\begin{array}{l}\text { Rompe récord nacional de jabalina. Mejor } \\
\text { atleta 1961. Medalla de oro en los III Juegos } \\
\text { Centroamericanos de Atletismo en Guatemala. }\end{array}$ \\
\hline Ana Cristina Ulloa & Voleibol & 1973-1986 & $\begin{array}{l}\text { Seleccionada nacional titular. Nueve primeros lugares } \\
\text { en campeonatos de Copa Centro Americana. }\end{array}$ \\
\hline $\begin{array}{l}\text { María del } \\
\text { Milagro París }\end{array}$ & Natación & 1969-1980 & $\begin{array}{l}\text { Desde los ocho años, edad en que inicia su carrera, obtiene } \\
\text { gran número de medallas a nivel nacional e internacional. } \\
\text { En 1980, es la primera atleta en clasificar a } \\
\text { una final olímpica, esto en Moscú; clasificó } \\
\text { de séptima en } 100 \text { metros mariposa. }\end{array}$ \\
\hline Silvia Poll Ahrens & Natación & 1979-1994 & $\begin{array}{l}\text { A cargo del entrenador Francisco Rivas, se convierte } \\
\text { una atleta de alto rendimiento, cosechando } \\
\text { grandes triunfos. Su máximo logro fue la medalla } \\
\text { olímpica de plata en } 200 \text { metros estilo libre. }\end{array}$ \\
\hline $\begin{array}{l}\text { Claudia Poll } \\
\text { Ahrens }\end{array}$ & Natación & 1979-2000 & $\begin{array}{l}\text { Después de muchos logros internacionales, participa } \\
\text { en } 1996 \text { en los Juegos Olímpicos de Atlanta, donde gana } \\
\text { la primera medalla de oro olímpica para Costa Rica. }\end{array}$ \\
\hline
\end{tabular}

Fuente: Inamu (2011)

Es notable el protagonismo de la Escuela Superior de Señoritas en la formación de la mujer costarricense desde 1888, al brindar aportes en varias áreas, incluso en el deporte. Esta institución se convierte en pilar de la construcción de nuestra sociedad porque fue la primera en preparar y graduar de secundaria a numerosas mujeres en el país.

Este colegio está muy ligado al origen del movimiento femenino en Costa Rica, pues en algunas oportunidades encabezó protestas en las calles por defender los derechos de las mujeres. Aparentemente, recibía estudiantes de diferentes clases sociales, por la ayuda que brindaba el Estado para las mujeres de zonas alejadas. Sin embargo, era una minoría; la mayoría eran mujeres de clase alta, hijas de hacendados. En el deporte, esta escuela fomenta 
los equipos de baloncesto, gracias a la formación dada por las encargadas del centro.

Vale la pena recordar a las valientes mujeres que en 1949 formaron el Deportivo Femenino de Costa Rica F. C., el primer equipo de fútbol femenino en Costa Rica. En 1951 jugaron contra Guatemala y en 1954 contra Cuba, en partidos de exhibición. Estas mujeres rompieron esquemas al insertarse en un espacio que por años fue exclusivo para hombres, mostrando a otras mujeres la posibilidad de incursionar en el fútbol y otros deportes. Sin duda, ayudaron a romper estereotipos del deporte femenino.

\section{METOdOLOGÍA}

Se seleccionaron dos medios de comunicación escrita que contienen noticias deportivas y con buena circulación nacional: los periódicos La Nación y Al Día. Se analizaron en cada uno las primeras dos semanas del mes de noviembre del 2011. Se contabilizó el número de líneas de texto dedicadas a información deportiva (sin incluir títulos ni subtítulos), al igual que las imágenes y periodistas, para comparar el protagonismo que da cada periódico a las noticias femeninas y masculinas, así como para determinar quiénes escriben esa información, para comparar, contrastar y relacionar. Cada línea mide 4,5 centímetros y están ubicadas en columnas.

Las noticias documentadas para este trabajo corresponden a deportistas, directivos, entrenadores y, en general, toda información vinculada con el deporte individual o colectivo. No se contemplaron entrevistas. Se contabilizaron los y las periodistas por noticias; es importante recalcar que algunos publican varios artículos el mismo día.

\section{RESULTADOS}

Sobre el análisis realizado en el periódico La Nación, la tabla 3 muestra que la cantidad de líneas escritas, vinculadas a noticias deportivas, es mucho mayor para el caso de los hombres en relación con el de las mujeres; lo mismo ocurre con las imágenes, y las noticias redactadas en su mayoría corresponden a periodistas hombres. Estos resultados mantienen una constante por día, por semana y en las dos semanas.

Tabla 3. Análisis sección deportiva, periódico La Nación

\begin{tabular}{|c|c|c|c|c|c|c|}
\hline Día & $\begin{array}{c}\text { Líneas } \\
\text { Hombres }\end{array}$ & $\begin{array}{c}\text { Líneas } \\
\text { mujeres }\end{array}$ & $\begin{array}{l}\text { Imágenes } \\
\text { Hombres }\end{array}$ & $\begin{array}{c}\text { Imágenes } \\
\text { Mujeres }\end{array}$ & $\begin{array}{c}\text { Periodistas } \\
\text { hombres }\end{array}$ & $\begin{array}{c}\text { Periodistas } \\
\text { Mujeres }\end{array}$ \\
\hline 1 & 546 & 28 & 20 & 2 & 7 & 1 \\
\hline 2 & 784 & 54 & 20 & 1 & 10 & 2 \\
\hline 3 & 852 & - & 23 & - & 11 & - \\
\hline 4 & 832 & 58 & 27 & 3 & 12 & 2 \\
\hline 5 & 639 & 108 & 17 & 4 & 8 & 2 \\
\hline 6 & 1205 & - & 28 & 3 & 16 & - \\
\hline 7 & 1758 & 24 & 34 & 1 & 22 & 4 \\
\hline 8 & 659 & - & 13 & - & 12 & - \\
\hline 9 & 1133 & - & 24 & - & 15 & - \\
\hline 10 & 970 & 17 & 33 & 1 & 17 & - \\
\hline 11 & 1054 & - & 20 & 1 & 13 & 1 \\
\hline 12 & 894 & - & 25 & - & 8 & 2 \\
\hline 13 & 1120 & 5 & 34 & - & 11 & - \\
\hline TOTAL & 12.446 & 294 & 318 & 16 & 162 & 14 \\
\hline
\end{tabular}

Fuente: Periódico La Nación, noviembre de 2011. Sección deportiva, análisis realizado. 
El periódico Al Día presenta un panorama similar, como se muestra en la tabla 4. Sin embargo, se observa un aumento en las líneas dedicadas a deporte relacionado con mujeres, y una disminución en las líneas dedicadas a deporte relacionado con hombres, si se compara con el periódico La Nación durante las dos semanas estudiadas.

Tabla 4. Análisis sección deportiva, periódico Al Día

\begin{tabular}{|c|c|c|c|c|c|c|}
\hline Día & $\begin{array}{c}\text { Líneas } \\
\text { Hombres }\end{array}$ & $\begin{array}{c}\text { Líneas } \\
\text { mujeres }\end{array}$ & $\begin{array}{c}\text { Imágenes } \\
\text { Hombres }\end{array}$ & $\begin{array}{c}\text { Imágenes } \\
\text { Mujeres }\end{array}$ & $\begin{array}{c}\text { Periodistas } \\
\text { hombres }\end{array}$ & $\begin{array}{c}\text { Periodistas } \\
\text { Mujeres }\end{array}$ \\
\hline 1 & 860 & 66 & 25 & 2 & 15 & - \\
\hline 2 & 1008 & 65 & 26 & 1 & 15 & 2 \\
\hline 3 & 674 & - & 27 & - & 11 & 1 \\
\hline 4 & 901 & 19 & 36 & 5 & 14 & 3 \\
\hline 5 & 682 & 38 & 26 & 1 & 11 & - \\
\hline 6 & 699 & 23 & 22 & 1 & 5 & 2 \\
\hline 7 & 968 & 6 & 36 & 2 & 10 & 4 \\
\hline 8 & 963 & 84 & 34 & 4 & 17 & 2 \\
\hline 9 & 608 & - & 50 & - & 10 & - \\
\hline 10 & 728 & 26 & 35 & 1 & 14 & 1 \\
\hline 11 & 760 & - & 23 & - & 13 & 1 \\
\hline 12 & 813 & - & 39 & - & 11 & - \\
\hline 13 & 657 & 36 & 23 & 1 & 10 & 2 \\
\hline TOTAL & $\mathbf{1 0 3 2 1}$ & $\mathbf{3 6 3}$ & $\mathbf{4 0 2}$ & $\mathbf{1 8}$ & $\mathbf{1 5 6}$ & $\mathbf{1 8}$ \\
\hline
\end{tabular}

Fuente: Periódico Al Día, noviembre de 2011. Sección deportiva, análisis realizado.

El gráfico 1 representa el número de líneas escritas, de lo cual pueden surgir diferentes interpretaciones. Por ejemplo, alguien podría concluir que:

- Las mujeres practican poco deporte y por ese motivo no se presentan las noticias en los periódicos analizados.

- El deporte es dirigido por hombres y para los hombres; por lo tanto los productos de los medios de comunicación escrita son dirigidos a los varones.

- Pocas mujeres practican deportes populares como el fútbol (noticias más presentadas en los medios analizados), pero es posible que practiquen otros deportes.

- Son pocas las mujeres que practican deportes competitivos o pocos sus logros y, por tanto, no se publican.

Son múltiples las causas que se podrían interpretar de los resultados, pero los datos del gráfico 1 van más allá: representan la opresión hacia la mujer, la preponderancia de la sociedad patriarcal, la reducción de la mujer a espacios privados y la continuidad de un estereotipo de mujer marcado con una feminidad igualmente estereotipada, que no se asocia con el deporte.

El gráfico 2 muestra cómo los hombres son los que redactan las noticias y las circulan en los medios, con una limitada participación de la mujer periodista. Se podría interpretar que en Costa Rica, en su mayoría, los periodistas son hombres. Sin embargo, se relaciona con que se considera que solo ellos pueden incursionar en el saber del deporte, principalmente porque la mayoría de las noticias son de fútbol, y se afilia este deporte a lo masculino, no con mujeres; por tanto, son ellos quienes pueden referirse al tema. No solo se muestra un espacio dominado por hombres, sino una manipulación de la información, orientada a invisibilizar a la mujer.

Existe consistencia entre los datos mostrados en los gráficos 1 y 2, de la información emanada de las tablas 3 y 4 . Es importante cómo se comprende la información reci- 
Gráfico 1. Comparación de líneas de texto

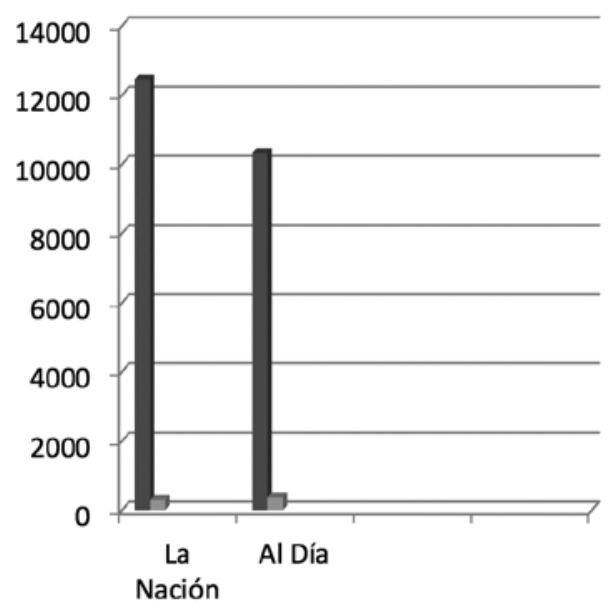

- Líneas de hombres

- Líneas de mujeres

Fuente: Análisis de la sección deportiva de los periódicos La Nación y Al Día. Noviembre de 2011.

Gráfico 2. Comparación de imágenes y periodistas

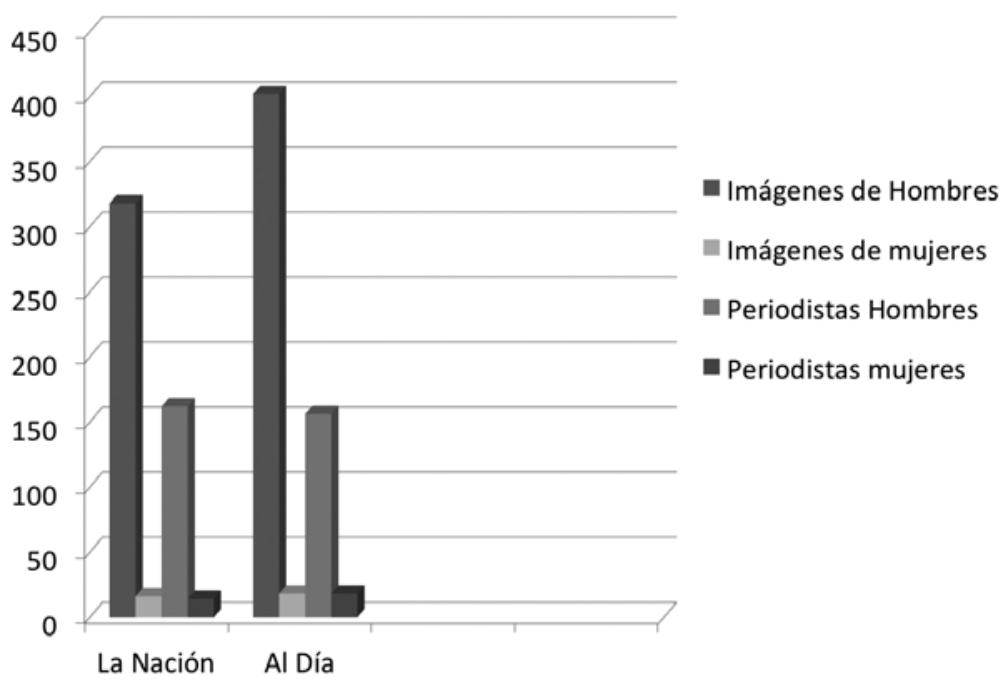

Fuente: Sección deportiva de los periódicos La Nación y Al Día. Noviembre de 2011.

bida; muchas personas leen el periódico cada mañana, pero ¿cuántas se detienen a comprender la información, para determinar bajo qué concepción está redactada y presentada? es posible que las respuestas abran el cuestionamiento y la reflexión, al generar diversidad de respuestas, como lo menciona Nietzsche (1888) al afirmar que de los hechos "solo hay interpretaciones" (Aforismo 481). Lo que se considera un conocimiento puede mostrar diferentes interpretaciones y perspectivas, dando paso a la pluralidad; aunado a lo anterior, este mismo autor indica que "hay muchas especies de ojos... por consiguiente, hay varias verdades" (Aforismo 540).

Como se presenta en el apartado de historia de esta investigación, el deporte desde sus inicios fue instaurado por y para el hombre. Por años, esta creencia se consideró como una verdad social, que fortaleció el poder patriarcal, colaboró con la construcción de un mundo misógino y androcéntrico. Esto invita a cuestionar las bases del deporte y las ideas preconcebidas consideradas como verdades absolutas. 
Los datos reflejan el sometimiento de la mujer, en el transcurso de la historia, a un sistema patriarcal que consolida el poder del hombre, desde la ideología deportiva. Rich (1996) se refiere al patriarcado como el poder de los padres:

... un sistema familiar, social, ideológico y político en el que los hombres (a través de la fuerza, la opresión, los rituales, la tradición, la ley, el lenguaje, las costumbres, la etiqueta, la educación y la división del trabajo) deciden cuál es o no es el papel que las mujeres deben interpretar y en el que las mujeres están en toda circunstancia sometidas al varón (p. 104).

El mensaje que brindan los medios de comunicación analizados es "el papel de que la mujer no calza en el ámbito deportivo; este es un espacio para hombres. Nosotros somos los que practicamos deportes, los que obtenemos logros deportivos importantes y eso es lo que vale la pena mostrar". Lo anterior permite al hombre mantener estatus y poder sobre la mujer, relegándola a espacios que no sean públicos.

Esa opresión que menciona Rich (1996) es tratada a profundidad por Marion (2000) en el texto Las cinco caras de la opresión (p. 77), donde define opresión como “...las desventajas e injusticias que sufre alguna gente... por las prácticas cotidianas... sus causas están insertas en normas, hábitos y símbolos que no se cuestionan" (p. 75). Los gráficos 1 y 2 muestran opresión hacia la mujer con una evidente desventaja, en relación con el hombre, expresada hacia la colectividad por medio de la prensa escrita, con un mensaje que no se cuestiona, pues la misma población es quien naturaliza e institucionaliza estereotipos deportivos.

Es una injusticia que la mujer sea invisibilizada en el espacio público. Se debe dar oportunidad a las mujeres para proyectar su participación en el deporte, sin importar edad, condición física, condición mental, apariencia o raza. Gatens (2002) manifiesta que "la igualdad, la riqueza y la oportunidad radican en la esfera pública" (p. 137), por eso es importante luchar por acceso a la esfera pública, ya que los resultados explicitan exclusividad del hombre, asignando unos roles y tareas para hombres y otros para mujeres, que según Gatens (2000) permiten "construir tipos específicos de sujetos" (p. 140).

\section{PROPUESTA}

Se proponen las siguientes acciones, en procura de la visibilización del deporte femenino en Costa Rica:
- Promover mayor participación de la mujer en la dirección, la gestión, el periodismo y la investigación sobre el deporte.

- Las instituciones relacionadas con la formación deben brindar capacitaciones, a nivel nacional e internacional, a las mujeres, para insertarse en los ámbitos del arbitraje, los jueces y el entrenamiento deportivo, en las diferentes disciplinas.

- La clase de Educación Física es un medio para superar prejuicios y estereotipos sobre el deporte femenino. Por lo anterior, la postura de este profesional debe ser acorde con esta igualdad deportiva, promoviendo en hombres y mujeres igual participación deportiva en actividades de la institución y externas.

- El Estado debe dotar de diferente material deportivo a las instituciones educativas, para introducir deportes variados en la clase de Educación Física, de manera que las mujeres puedan practicar no solo los tradicionales, como el voleibol, el baloncesto, la natación, el atletismo y el fútbol.

- Las diferentes universidades que forman profesionales en Educación Física deben hacerlo bajo una perspectiva de género, dejando de lado estereotipos aprendidos.

- Las instituciones educativas, con ayuda del profesional de Educación Física, deben capacitar a las familias para que tengan una influencia positiva sobre las mujeres deportistas, de manera que su apoyo sea constante.

- Promover la investigación sobre el tema "Mujer y deporte en Costa Rica”, para que los resultados se puedan aplicar, y no basarse solo en investigaciones internacionales.

- Los medios de comunicación deben producir programas deportivos e informativos, que ofrezcan una manera diferente de ver a la mujer deportista.

- Los medios de comunicación han de proyectar a las mujeres deportistas con mayor fuerza, realizando entrevistas y reportajes sobre sus logros.

- Dar la posibilidad a la mujer de protagonizar espacios deportivos en los medios de comunicación, para influir positivamente en un mundo deportivo construido por hombres.

- Visibilizar los logros de las mujeres en el deporte por medio de la prensa escrita. 
- Permitir que las mujeres puedan tomar decisiones importantes sobre el deporte costarricense.

- Promover la práctica de los deportes de conjunto de forma mixta, no solo a nivel recreativo, sino también competitivo. Los rendimientos deportivos entre hombres y mujeres son diferentes, pero se pueden complementar. Lo anterior implica un cambio de normativas y reglamentos nacionales e internacionales.

- Mayor aporte y soporte de los movimientos feministas en el ámbito deportivo.

\section{CONCLUSIONES}

Es claro el progreso de la incursión de la mujer en el deporte desde 1894, cuando Coubertin prohíbe su participación en los Juegos Olímpicos, hasta la era moderna. Por estos logros se debe brindar reconocimiento a los movimientos feministas, que generaron nuevos saberes y nuevas líneas interpretativas, visibilizando a las mujeres.

En la actualidad la lucha que se debe dar es por la visibilización de la mujer en los espacios públicos, con la ayuda de los medios de comunicación; iniciar a nivel local y posteriormente a nivel nacional, para romper estereotipos deportivos que oprimen a las mujeres, y así modificar la forma de pensar, sentir y actuar de la sociedad.

Los dos medios de comunicación escrita estudiados limitan la cobertura de eventos deportivos en los que las mujeres tengan participación o decisión; en los casos en que la mujer fue mencionada, se perfiló como acompañante de los deportistas a eventos, o futbolistas mujeres con logros internacionales. Los significados y las representaciones de la mujer pueden deconstruirse, viendo, en lo que se muestra, lo invisible.

Se puede concluir de manera general que a nivel nacional e internacional se ha abierto espacio a la mujer para la práctica deportiva; esto permite afirmar que no está del todo invisibilizada, en comparación con otras épocas. No obstante, los resultados muestran una invisibilización en el espacio público, considerado como una de las tantas maneras en que operan la dominación, la exclusión, la opresión y la discriminación.

\section{REFERENCIAS}

Antúnez, M. (2001). Reflexiones acerca de lo que la mujer representa para el deporte y el verdadero significado del deporte para la mujer. Revista Digital Efdeportes. Recuperado de http://www.efdeportes.com/.

Barbero, J. (1993). Materiales de sociología del deporte. España: Ediciones de la Piqueta.

Cuevas, B. (2009). Cuerpo, feminidad y consumismo: el caso de jóvenes universitarias. Revista de Ciencias Sociales, 123-124(1-2), 79-92.

Bostrom, N. (2005). Una historia del pensamiento transhumanista. Diario de la evolución y la Tecnología, 14 (1). New York: McMillan.

Comisión Nacional de Cultura Física y Deporte (Conade) e Instituto Nacional de las Mujeres (Inmujeres). (s. f.). Mujer y deporte, una visión de género. México.

Derrida, J. (1968). La Différance. Escuela de Filosofía. Universidad de Arcis. Recuperado de www. philosophia.cl

Foucault, M. (1968). Las palabras y las cosas: una arqueología de las Ciencias Humanas. Argentina: Ediciones Siglo Veintiuno.

Gallo, C. L; Monsalve, T. D.; Castro, C. J.; Hopl, H; Agudelo, F. 1.; y Ochoa, P.V. (2000). Participación de las mujeres en el deporte y su rol social en el área metropolitana del Valle del Aburrá. Revista Digital Efdeportes. Medellín, Colombia. Recuperado de: http://www.efdeportes.com/efd27a/mujerm.htm

Gatgens, M. (2002). El poder, los cuerpos y las diferencias. En Desestabilizar la teoría. México: pueg.

Hall, S. (s. f). Significado, representación, ideología: Althusser y los debates postestructuralistas. Recuperado de http://www.ram-wan.net/restrepo/ hall/althusser $\% 20 \mathrm{y} \% 20 \operatorname{los} \% 20$ debates $\% 20$ postestructuralistas.pdf

Hernández, E. (1999). Igualdad en el deporte. Principal reto hacia el 2000. Fem, 23 (198).

Hook, C. (s. f.). Encyclopedia of Bioethics. New York: McMillan.

Instituto Nacional de la mujer. (2005). Mujeres destacadas de Costa Rica. San José, Costa Rica.

Instituto Nacional de la Mujer. (2011). Galería del deporte. San José, Costa Rica.

Kellner, D. (s. f.). Media Culture and the Triumph of the Spectacle. Recuperado de http://pages.gseis.ucla.edu/ faculty/kellner/papers/medculturespectacle.html 
López, G. (1990). Mujer y deporte: historia de una sola palabra. Fem, 14 (85).

Macías, V. (1999). Estereotipos y deporte femenino. La influencia del estereotipo en la práctica deportiva de niñas y adolescentes. Tesis doctoral, Departamento de Psicología Social y Metodología de las Ciencias del Comportamiento, Universidad de Granada. Granada, España.

Marion, I. (2000). Las cinco caras de la opresión. En La injusticia y la política de la diferencia. Madrid: Ediciones Cátedra.

Nietzsche, F. (1888). La voluntad de dominio. Ensayo de una transmutación de todos los valores. Tomo 8. Madrid: EDAF.

Real Academia Española (2001). Diccionario de la lengua española. Vigésima segunda edición. España.

Rich, A. (1996). El reino de los padres. Nacemos de la mujer: maternidad como existencia e institución. Madrid: Ediciones Cátedra.
Rodríguez, T. D., Martínez, P. M. y Mateos, P. C. (2004). Identidad y estereotipos de la mujer en el deporte. Una aproximación a la evolución histórica. Recuperado de http://webs.uvigo.es/reined/ojs/index.php/reined/ article/viewFile/16/7

Tusell, J. (2009). Deporte y discriminación por sexo: fútbol, remo y salto de esquí. Revista para el Análisis del Desarrollo. Recuperado de www.indret.com

Vargas, V. (2002). Los feminismos latinoamericanos en su tránsito al nuevo milenio (una lectura político personal). En Daniel Mato (coord.). Estudios y otras prácticas intelectuales latinoamericanas en cultura y poder. Caracas: Consejo Latinoamericano de Ciencias Sociales (Clacso) y CEAP, Faces, Universidad Central de Venezuela.

Vilanova, A. y Soler, S. (2008). Las mujeres, el deporte y los espacios públicos: ausencias y protagonismos. Apuntes Educación Física y Deportes. Recuperado de http://www.revista-apunts.com/es/ hemeroteca? article $=543$ 